\title{
Assessing the Contribution of Higher Education to Regional Development
}

\author{
Inna N. Sannikova \\ Altai State University \\ Galina A. Bulatova \\ Altai State University \\ Elena V. Kuzina \\ Altai State University
}

The paper deals with the issue of assessing the contribution of higher education to regional development. The study aims to analyze new ways of assessing the contribution of universities to regional development using such indicators as (1) their contribution to the local economy, (2) their role in human capital development, and (3) their contribution to the regional innovation system. We offer an objective assessment of the contribution of higher education to the regional economy by determining the relationship between personnel training and industrial specialization characteristics. Admissions are assigned to the transparency of regional education systems and the migration of university graduates. In general, regional industry specialization justifies regional contribution to the national gross domestic product. Therefore, regions that produce goods with a high share of value-added will always have advantages. The authors argue that quantitative indicators for assessing the role of universities in regional development should be supplemented with the results of sociological surveys that can be posted on digital platforms and services.

Keywords: regional development, role of universities, innovative ecosystem, regional economic development

\section{INTRODUCTION}

For more than 20 years, higher education has been a critical indicator of regional socio-economic development. There are several well-known examples of Western universities that are drivers of regional innovation and industrial clusters. However, today the world is changing. Universities are closely integrated into global research and education networks. It is quite challenging to determine the extent to which the location of such universities can affect the development of the region (Wolfe, 2005). Explicit (codified) knowledge generated at the global level is amenable to a scientometric formal assessment. As for implicit knowledge, which is primary for the development of territories and can only be evaluated through qualitative indicators and characteristics, often subjective ones.

Further analysis of the various degrees of influence of universities on territorial development leads to the formation of different university models, such as (1) the entrepreneurial university model, (2) the regional innovation system model, (3) the "mode two" university model, (4) the engaged university model 
(Trippl, Sinozic, Smith, 2014). In Russia, attempts are being made to create various university models: (1) national research universities; (2) a program to increase the international competitiveness of Russian universities (project "5-100"); (3) flagship universities. "Meanwhile, the policy of education development in Russia was focused primarily on solving the internal problems of the system, and not on contributing to the economic and social development of the country. Consequently, it was based on the concept of education as an area of social obligation" (p. 11). To meet the scale of socio-economic transformations that are the basis for implementing national projects, executive power should provide universities with the most effective transformation in accordance with the chosen model.

We should not underestimate the role of universities focused on international scientific research and networking programs in regional socio-economic development. For example, "a pilot project 'INO Tomsk' was launched in Tomsk to form a new look at the development of the region by means of concentrating private business efforts, federal, and regional resources <... " (Belyakov \& Novikova, 2017). Therefore, a formal tool for assessing the contribution of universities in the development of the region should be focused on a wide range of indicators. In this regard, we can agree with the Institute of Education of the Higher School of Economics, which offers three indicators for assessing the contribution of universities to regional development based on OECD practices: (1) contribution to the regional economy; (2) its role in the development of human capital, and (3) its contribution to the innovative regional system (Center for Strategic Research and the Higher School of Economics, 2018; Leshukov, Evseeva, Gromov \& Platonova, 2017).

\section{MATERIALS AND METHODS}

In this paper, we analyze the possibility of using indicators to assess the contribution of universities to regional development. No issue arises regarding "economic block." In general, the contribution of universities to the development of this block can be defined as the attraction of funds to the region. There is no doubt that the indicator "the ratio of income from personal income tax of university employees to the volume of total income from personal income tax to the regional budget" characterizes the contribution of the university to the formation of the revenue part of the budget. From the point of view of generating cash flow, universities can play a significant role in the economy of regions with little funds raised or an inefficient structure. Assessing the impact of human capital development, one should note that the concept of "human capital" is a very controversial issue. There are many methodological approaches to measuring human capital based on the cost principle, ranging from a minimum set of costs for training, education, and medicine to a broad understanding of investment in the development of creative ideas and economic freedoms.

The discount method is also used for a given return rate on all national wealth. This approach involves using the following indicators: (1) "premium for higher education" and "share of employed graduates." As a basis for these indicators, we can refer to studies that prove that the wages of people with higher education exceed the salary of people without higher education. We can also mention the studies showing a significant dependence of the Gross Domestic Product [GRP] growth rate on the share of the working-age population with higher education (Egorov, Leshukov \& Gromov, 2017). Thus, a study conducted by the Higher School of Economics in 2015 showed that the average salary of employees with higher education (43,362 rubles) is 1.3 times higher than the average salary in the country (32,911 rubles) (Bondarenko, Gokhberg \& Kuzminov 2017; Center for Strategic Research and the Higher School of Economics, 2018).

University graduates have a higher level of economic activity. According to the Rosstat survey, the level of participation of graduates in the labor force in 2016-2018 reached $87.8 \%$, including $89.1 \%$ of graduates with higher education, $86.3 \%$ with secondary vocational education in training programs for middle-level specialists, and $85.0 \%$ with secondary vocational education in training programs for qualified workers. Employment participation rates for these groups of graduates were $82.7 \%, 76.5 \%$, and $73.5 \%$, respectively (Federal State Statistics Service, 2019).

The results of monitoring by the Ministry of Education and Science on the employment of university graduates in 2015-2016 showed that a higher education diploma allows the vast majority (75\%) of 
university graduates to find a job. According to the monitoring data, the employment rate of graduates in Altai Krai was $80 \%$, while $65 \%$ were employed in the region. The average amount of payments to university graduates is 22,933 rubles. For comparison, the corresponding figures were $60 \%, 70 \%$, and 16,482 rubles for graduates of secondary vocational schools (The Ministry of Education and Science of the Russian Federation, 2016).

However, it is still unknown how many university graduates hold positions requiring higher education and correspond to the professional training profile.

In this regard, the quality of education becomes controversial since there is no precise assessment tool and an apparent link with the GRP growth rate, provided that there is a gap between the number of graduates and jobs directly related to the needs of the regional labor market. For example, the gap between graduates of humanities majors with high-quality training and theses. In any case, the use of this "economic block" allows one to assess the indirect impact on the development of human capital.

The indicator "contribution to the innovative development of the region" raises much concern. In particular, the indicators "the number of citations of publications in the Russian Science Citation Index [RSCI]" and "number of citations of publications in Scopus." Citation is widely used in international and Russian practice with the aim of (1) building various ratings, (2) establishing university models, and (3) stimulating activity. However, no reliable studies are currently establishing a definite relationship between the number of publications, citations, and innovative activity growth.

Research interests of Russian scholars mainly concern the study of the relationship between material incentives and publication activity growth (citation). The situation is different for foreign specialists focused on comparing the thematic structure of publications and calculating the scientific specialization index. The weak point in including these indicators in assessing the impact of universities on regional development is the low quality of publications and unreliable citations. Therefore, formally known as the Commission for Counteracting the Falsification of Scientific Research, the RAS Commission addressed the editorial office with a proposal to retract 2528 articles in July 2019 (KPFRAN, 2019). This fact can be considered a natural result of using a formal quantitative indicator to assess the activities of universities and teaching staff.

The objectivity of assessing the contribution of universities to the regional economy can be assessed by analyzing the relevance of the structure of personnel training and industry specialization. Admissions in this analysis are determined by the transparency of regional education systems and the migration of university graduates.

\section{RESULTS}

We analyzed the graduate training scheme based on the monitoring data of the Main Information Computing Center of the Federal Agency for Education of the Russian Federation. In addition, we compared the compliance of the all-Russian training graduate scheme with the graduate training scheme in the Siberian Federal District. According to the monitoring data, the number of students enrolled in higher education programs reached 4,174,944 across Russia. The students were grouped according to the following training areas: (1) "art and culture"; (2) "mathematics and science"; (3) "engineering, technology and technical science"; (4) "healthcare and medical science"; (5) "agriculture and agricultural science"; (6) "social science"; (7) "education and pedagogical science," and "human science." 


\section{FIGURE 1 \\ THE PROFILE OF STUDENT COMMUNITIES OF THE RUSSIAN FEDERATION [RF] AND SIBERIAN FEDERAL DISTRICT [SFD], ACCORDING TO THE UNIVERSITY MONITORING DATA FOR 2018}

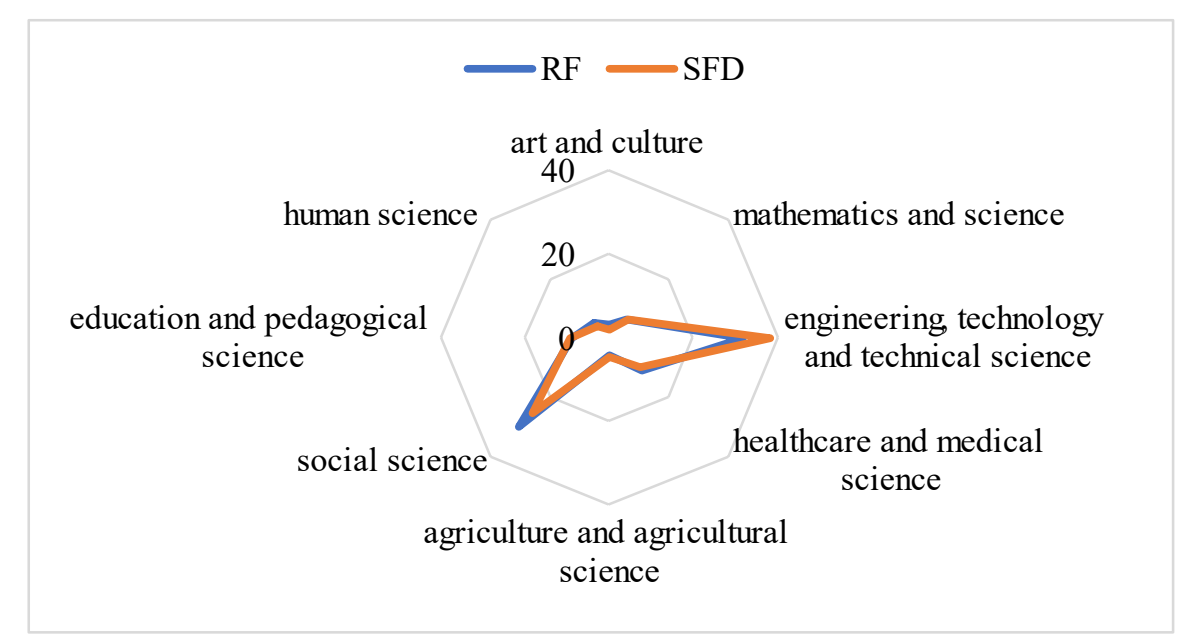

Fig. 1 shows that the training program for students in the main areas of training in the Siberian Federal District mainly corresponds to the training program for students in Russia (Main Information and Computing Center of the Ministry of Education and Science of Russia, 2019).

The most considerable discrepancies are observed in the following areas: (1) the program for training students in the field of "engineering, technology and technical science" in the Siberian Federal District exceeds the average number in Russia by 6.23 percentage points; and the program for training students in the field of "social science" is 4.6 percentage points less in the Siberian Federal District than the average number in Russia. Deviations in other areas of study are insignificant. On the one hand, this structural deviation can be explained by the presence in the Siberian regions of large technical universities created during the industrial development of Siberia in the Soviet era. On the other hand, these universities were created on the basis of educational institutions evacuated during the Great Patriotic War by allocating a large number of grants for free admission to universities in technical areas of training.

In this regard, we present the results of comparing the training program for students in the main areas of training with the average Russian training profile in one of the regions of the Siberian Federal District, Altai Krai. 


\section{FIGURE 2 \\ THE PROFILE OF STUDENT COMMUNITIES OF THE RUSSIAN FEDERATION [RF] AND ALTAI KRAI, ACCORDING TO THE MONITORING DATA IN 2018}

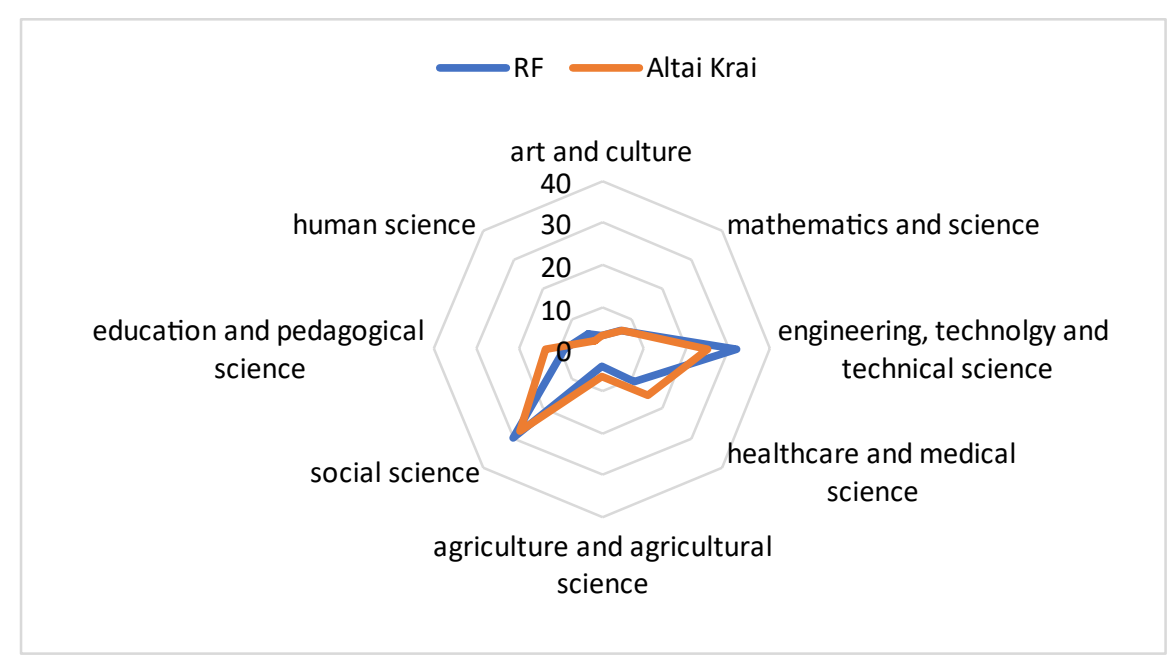

Fig. 2 shows more significant structural deviations in personnel training in the higher education system of Altai Krai in comparison with the average Russian training profile and the average training program in the Siberian Federal District (Federal State Statistics Service, 2019).

We see significant deviations in the training program in the main areas of training in the Altai territory compared to the national average, namely: (1) in "engineering, technology and technical science" -6.74 percentage points less than the national average; (2) in "health and medical science" -4.53 percentage points more than the national average; (3) in "education and pedagogical science" - 4.51 percentage points more than the national average.; (4) in social studies - 2.71 percentage points less than the national average; (5) agriculture and agricultural science -2.50 percentage points more than the national average. The training program for graduates of Altai Krai differs significantly from the average Russian training program and the average program of the Siberian Federal District. In our view, the sectoral structure of the regional economy provides the cause and effect of this discrepancy.

Finally, the analysis should be supplemented with a comparison of the training program for students in the main areas of training in the Central Federal District with the average Russian indicators, since the Central Federal District accounts for the most significant number of students $(1,290,408)$, which is $31 \%$ of the total number of students in Russia. Furthermore, this district represents the maximum "student migration" of the most talented and prepared applicants from the regions to Moscow universities. 


\section{FIGURE 3 \\ THE PROFILE OF THE STUDENT COMMUNITY OF RF AND CENTRAL FEDERAL DISTRICT [CFD], ACCORDING TO THE MONITORING DATA IN 2018}

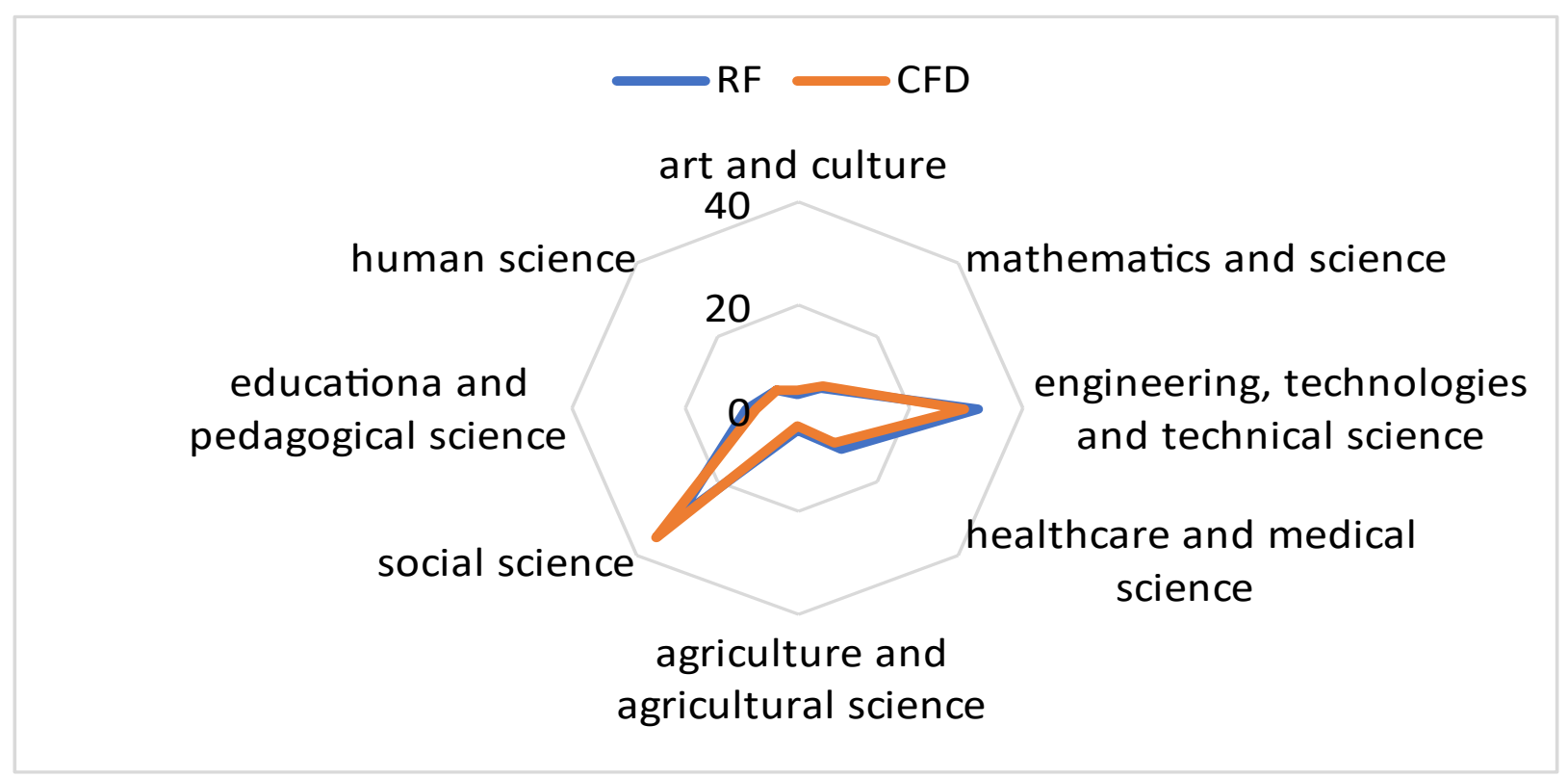

Given that most students are from the Central Federal District, we can observe minimal discrepancies between the program of training students in the main areas of higher education in the Central Federal District and the average Russian indicators. The maximum deviations are recorded in the following areas of training: (1) "social studies" - in the Central Federal District is 4.79 percentage points higher than the average Russian level and "mechanical engineering, technology and technical science" - in the Central Federal District is 2.5 percentage points lower than the average Russian level.

A comparative analysis revealed similar training areas in the Siberian Federal District, but with an inverse relationship. In the Siberian Federal District, most students are trained in "engineering, technology and technical science," while in the Central Federal District, most students are trained in "social science." The reduction of grants for the program "social studies" results from numerous statements about an "overabundance" of economists and lawyers, primarily in regional universities. Therefore, this leads to a wider gap in the vocational training program in the Central Federal District and regions of other federal districts.

From the point of view of the role of higher education in the development of professional training programs for the regional economy, it is advisable to correlate the educational programs of the main areas of training with the structure of the domestic regional product, emphasizing the types of economic activities that are most relevant for university monitoring (Unified interdepartmental information and statistical system of the Russian Federation, 2019). 
TABLE 1

GRP STRUCTURE, 2018

\begin{tabular}{|c|c|c|c|c|c|c|c|c|}
\hline \multirow{2}{*}{$\begin{array}{c}\text { Types of economic } \\
\text { activity }\end{array}$} & \multicolumn{2}{|l|}{ RF } & \multicolumn{2}{|l|}{ CFD } & \multicolumn{2}{|l|}{ SFD } & \multicolumn{2}{|c|}{ Altai Krai } \\
\hline & mln.RUB & $\%$ & mln.RUB & $\%$ & mln.RUB & $\%$ & mln.RUB & $\%$ \\
\hline 1. Agriculture & $3,668,029$ & 4.32 & 914,785 & 3.11 & 368,275 & 4.42 & 73,953 & 13.45 \\
\hline $\begin{array}{ll}\text { 2. } & \text { Mining and } \\
\text { manufacturing } \\
\text { industry, energy, } \\
\text { and } \\
\text { communications }\end{array}$ & $44,774,115$ & 52.69 & $11,640,074$ & 39.57 & $5,098,928$ & 61.19 & 205,832 & 37.42 \\
\hline 3. Education & $2,571,805$ & 3.02 & 787,055 & 2.68 & 299,441 & 3.59 & 27,102 & 4.93 \\
\hline 4. Healthcare & $3,447,796$ & 4.06 & $1,043,114$ & 3.55 & 369,592 & 4.44 & 33,659 & 6.12 \\
\hline $\begin{array}{ll}\text { 5. } & \text { Culture and } \\
\text { sport }\end{array}$ & 728,046 & 0.86 & 291,727 & 0.99 & 52,671 & 0.63 & 3,914 & 0.71 \\
\hline 6. Other activities & $29,786,933$ & 35.05 & $14,735,191$ & 50.10 & $2,143,519$ & 25.73 & 205,513 & 37.37 \\
\hline 7. $\quad$ Total & $84,976,724$ & 100 & $29,411,946$ & 100 & $8,332,426$ & 100 & 549,973 & 100 \\
\hline
\end{tabular}

Table 1 (Federal State Statistics Service, 2019). shows the GRP structure by type of activity; the data were aggregated:

- "Agriculture" - agriculture, forestry, hunting, fishing, and fish farming;

- "Mining and manufacturing industry" - mining, manufacturing, construction, provision of electrical energy, gas and steam, air conditioning, water supply, sanitation, waste management and collection, pollution elimination activity, information, and communication activity;

- "Education";

- "Healthcare" - activities in the field of health and social services;

- "Culture and sport" - activities in the field of culture, sports, leisure, and entertainment;

- "Other activities" - other activities in accordance with the Russian National Classifier of Types of Economic Activity [RNCE] 2.

Comparing the data on the profile of the student community and the structure of GRP, we can note the correlation between the Central Federal District, the Siberian Federal District, and the entire Russian Federation. It is quite natural that in the Central Federal district, "other activities" make up half of the GRP (35\% of the GDP of Russia), which includes all services related to management, finance, administrative activities, or trade. In the Siberian Federal District, the main share of GRP (less than 10\% of GDP of Russia) is invested in the industry, energy, construction, and communications, which correlates with the predominant share of the student training program in the field of "engineering, technology and technical science."

The structure of the GRP of Altai Krai (0.6\% of GDP and less than 7\% of GRP in the Siberian Federal District) is significantly different from the average Russian level and the level of the Siberian Federal District. The share of agriculture is noticeable (more than 9 points higher than the average Russian level and the level of the Siberian Federal District) and significantly lower than the share of the real economy excluding agriculture (15.27 percentage points from the average Russian level and 23.77 percentage points from the Siberian Federal District). A significant share of GRP, among other activities, is determined mainly by trade. In general, the profile of students in Altai Krai correlates with the structure of GRP and explains the mutual influence of regional industry specialization and regional higher education training programs. Therefore, industry-specific regional specialization explains the regional contribution to national GDP. For instance, agricultural specialization accounts for a significant lag behind the national average since regions where entrepreneurs focus on product manufacturing with a high share of value-added will always have an advantage. 


\section{DISCUSSION}

In addition to identifying inconsistencies in the formal assessment of the impact of universities on regional development, we should note that this is a combined assessment of the impact of all universities. Although it is possible to assess the individual contribution of each university, the result of the assessment will be with an increasing error. For this reason, it is advisable to supplement the formalized set of indicators with a qualitative component.

First of all, these goals can best be achieved by studying the involvement of higher education institutions in the processes of regional socio-economic strategic planning, both actors and subjects of regional development with a specific role in regional and macro-regional strategies. This inclusion is indirectly manifested through the level of interaction between universities and regional (municipal) authorities, both executive and legislative.

Unfortunately, regional authorities do not take responsibility for the interaction with federal budget universities because of the adopted financial system, which is of primary importance for Russia. This circumstance negatively affects the strategic planning of regional socio-economic development. For instance, in the bill "Strategies for socio-economic development of Altai Krai until 2035," adopted in the first reading, the section "Education" sets the direction for pre-primary, secondary, and secondary vocational education. Also, there is a mention of the system of lifelong education, but there is no mention of the role of regional universities in the development of such a system.

The section "innovation strategy" mentions two universities, but it is not clear how to integrate and involve them in the innovation development system (Ministry of Economic Development of the Altai Krai, 2020). The introduction of formal quantitative indicators cannot ensure real interaction between universities and regional authorities. National strategic planning systems should ensure the active functioning of universities with a certain degree of responsibility. Active use of functionality can become one of the components of assessing the impact of universities on the development of the territory.

Second, the formalized set of quantitative indicators of the role of universities in the development of territories should be supplemented with sociological studies that clarify how regional residents assess the impact of universities on (1) the development of local communities, (2) the environment, (3) the urban environment, and (4) culture. There are both Russian and foreign studies by urbanists and sociologists on the impact of university locations on urban infrastructure changes (Dyba, 2017). However, in this case, sociology should study the entire spectrum of the impact of higher education on the environment (contribution to the development of culture or improvement of the environmental situation in the region).

Third, it is necessary to take into account the impact of the regional training program for students in the main areas of training on the economic development of the region, considering (1) the industry specialization and leading indicators, (2) the structure and topics of regional research, (3) design, and (4) survey work (Melamed-Varela, Navarro-Vargas, Blanco-Ariza \& Olivero-Vega, 2019). A separate part of higher education contribution to regional development should concern the impact on the environment and ecology (Mironov \& Sorokin, 2019).

\section{CONCLUSION}

Therefore, the quantitative indicators for assessing the role of universities in regional development should be supplemented with the results of sociological surveys that can be posted on digital platforms and services. Joint prompt assessment of the contribution of higher education to regional development should be carried out to implement corrective management decisions at all levels, promoting a "sustainable communication model" (Davini, Marchionne \& Pandolfini, 2019) that can consolidate the resources of universities and regions. Thus, joint assessment is the only way to determine the "third role of universities," which includes blocks for innovative ecosystems. 


\section{REFERENCES}

Belyakov, K., \& Novikova, E. (2017). The third role of universities. Retrieved from https://www.vedomosti.ru/opinion/articles/2017/10/02/736046-tretya-rol-universitetov

Bondarenko, N.V., Gokhberg, L.M., \& Kuzminov, Ya. I. (Eds.). (2017). Indicators of education in the Russian Federation 2017: Data book. Moscow, Russia: NRU, HSE.

Center for Strategic Research and the Higher School of Economics. (2018). 12 Solutions for a new education: Report. Retrieved from https://www.hse.ru/data/2018/04/06/1164671180/Doklad_obrazovanie_Web.pdf

Davini, V., Marchionne, I., \& Pandolfini, E. (2019). Generating a new idea of public mission for universities. In W.L. Filho \& U. Bardi (Eds.), Sustainability on university campuses: Learning, skills building and best practices (pp. 45-58). Cham, Switzerland: Springer. Retrieved from https://link.springer.com/chapter/10.1007/978-3-030-15864-4_4

Dyba, E. (2017). How the University Improves the Urban Environment. Retrieved from https://iq.hse.ru/news/186814654.html

Egorov, A.A., Leshukov, O.V., \& Gromov, A.D. (2017). The role of universities in economic development of Russian regions: Basic research program. Series: Education WP BRP 41/EDU/2017. Retrieved from https://wp.hse.ru/data/2017/05/15/1171306551/41EDU2017.pdf

Federal State Statistics Service. (2019). The result of selective research of workforce for the quarter I. Retrieved from http://www.gks.ru/wps/wcm/connect/rosstat_main/rosstat/ru/statistics/ publications/catalog/doc_1140097038766

KPFRAN. (2019, October 1). Report of the RAS Commission on combating the falsification of scientific research on the results of the hearings. Retrieved from https://kpfran.ru/2020/01/06/

Leshukov, O.V., Evseeva, D.G., Gromov, A.D., \& Platonova, D.P. (2017). Assessment of the contribution of regional higher education systems to the socio-economic development of Russian regions. High School of Economics. Series Modern Education Analytics, 3(11). Retrieved from https://ioe.hse.ru/data/2017/04/03/1168588296/CAO\%2011\%20электронный.pdf

Main Information and Computing Center of the Ministry of Education and Science of Russia. (2019). Information and analytical materials on the results of monitoring the effectiveness of higher education institutions. Retrieved from http://indicators.miccedu.ru/monitoring/?m=vpo

Melamed-Varela, E., Navarro-Vargas, L., Blanco-Ariza, A., \& Olivero-Vega, E. (2019). Vínculo Universidad-Empresa-Estado para el fomento de la innovación en sistemas regionales: Estudio documental. Retrieved from http://www.revistaestudiosregionales.com/documentos/articulos/pdfarticulo-2565.pdf

Ministry of Economic Development of the Altai Krai. (2020). The bill "Strategy for socio-economic development of Altai Krai for the period until 2035". Retrieved from https://econom22.ru/prognoz/strateg/

Ministry of Education and Science of the Russian Federation. (2016). Graduate employment monitoring. Retrieved from http://spo.graduate.edu.ru/\#/?year=2014\&year_monitoring=2016

Mironov, V.A., \& Sorokin, A.N. (Eds.). (2019). The role of the classical university in the development of regional geological works on the territory of Siberia. Proceedings from International Multidisciplinary Scientific Geo Conference. Albena, Bulgaria: SGEM.

Trippl, M., Sinozic, T., \& Smith, H.L. (2014). The role of universities in regional development: Conceptual models and policy institutions in the UK, Sweden and Austria. Lund, Sweden: Centre for Innovation, Research and Competence in the Learning Economy (CIRCLE) Lund University. Retrieved from http://wp.circle.lu.se/upload/CIRCLE/workingpapers/201413_Trippl_et_al.pdf

Unified interdepartmental information and statistical system of the Russian Federation. (2019). Gross Regional Product at Basic Prices (All-Russian Classifier of Economic Activities 2). Retrieved from https://fedstat.ru/indicator/59448

Wolfe, D.A. (2005). The role of universities in regional development and cluster formation. Retrieved from https://www.researchgate.net/publication/252390580_The_Role_of_Universities_ in_Regional_Development_and_Cluster_Formation 